\title{
Self-Regulation as a Mediator Between Sibling Relationship Quality and Early Adolescents' Positive and Negative Outcomes
}

\author{
Laura M. Padilla-Walker \\ Brigham Young University \\ James M. Harper \\ Brigham Young University \\ Alexander C. Jensen PhD \\ Brigham Young University, alexjensen@byu.edu
}

Follow this and additional works at: https://scholarsarchive.byu.edu/facpub

Part of the Psychology Commons

\section{Original Publication Citation}

Padilla-Walker, L. M., Harper, J. M., \& Jensen, A. C. (2010). Self regulation as a mediator between sibling relationship quality and early adolescents' positive and negative outcomes. Journal of Family Psychology, 24, 419-428. doi:10.1037/a0020387

\section{BYU ScholarsArchive Citation}

Padilla-Walker, Laura M.; Harper, James M.; and Jensen, Alexander C. PhD, "Self-Regulation as a Mediator Between Sibling Relationship Quality and Early Adolescents' Positive and Negative Outcomes" (2010). Faculty Publications. 3523.

https://scholarsarchive.byu.edu/facpub/3523

This Peer-Reviewed Article is brought to you for free and open access by BYU ScholarsArchive. It has been accepted for inclusion in Faculty Publications by an authorized administrator of BYU ScholarsArchive. For more information, please contact ellen_amatangelo@byu.edu. 


\title{
Self-Regulation as a Mediator Between Sibling Relationship Quality and Early Adolescents' Positive and Negative Outcomes
}

\author{
Laura M. Padilla-Walker, James M. Harper, and Alexander C. Jensen \\ Brigham Young University
}

\begin{abstract}
The current study examined the role of adolescents' self-regulation as a mediator between sibling relationship quality and adolescent outcomes, after controlling for the quality of the parent-child relationship. Participants were 395 families (282 two parent; 113 single parent) with an adolescent child ( $M$ age of child at Time $1=11.15, S D=.96,49 \%$ female) who took part in [project name masked for blind review] at both Time 1 and Time 2. Path analysis via structural equation modeling suggested that sibling affection was longitudinally and positively related to self-regulation and prosocial behaviors, and negatively related to externalizing behaviors; while sibling hostility was positively, and having a sister was negatively related to internalizing behaviors (in general, paths were stronger for adolescents from twovs. single-parent families). There was also evidence that adolescents' self-regulation partially mediated the relation between sibling affection and positive and negative adolescent outcomes. The discussion focuses on the importance of continued research examining the mechanisms through which the sibling relationship influences development during adolescence.
\end{abstract}

Keywords: sibling affection, sibling hostility, self-regulation

The sibling relationship is an important, yet understudied, aspect of socialization in the lives of children and adolescents. Each sibling dyad brings unique contributions to shaping the dynamics and environment of the family (Kramer \& Kowal, 2005; Updegraff, Thayer, Whiteman, Denning, \& McHale, 2005), and for many, this unique relationship also extends across the life course (Kramer \& Bank, 2005). Although sibling influences are not always examined in the context of additional family relationships, when they are, research suggests that sibling relationships are uniquely important to children's and adolescents' development, above and beyond the benefits of parenting (Criss \& Shaw, 2005; Pike, Coldwell, \& Dunn, 2005). However, fewer studies have sought to identify the mechanisms through which siblings exert a positive or negative influence on each other, and this is especially important during early adolescence when physical and cognitive shifts often lead to changes in family relationships (Steinberg \& Silk, 2002).

Laura M. Padilla-Walker, James M. Harper, and Alexander C. Jensen, School of Family Life, Brigham Young University.

We thank the Family Studies Center at BYU, the School of Family Life, and the College of Family Home and Social Science at BYU, and we recognize the generous support of the many private donors who provided support for this project. We also thank those families who were willing to spend valuable hours with our team in interviews, and the many students who assisted in conducting the interviews.

Correspondence concerning this article should be addressed to Laura Padilla-Walker, 2097 JFSB, School of Family Life, Brigham Young University, Provo, UT 84602. E-mail: laura_walker@byu.edu
Thus, the current study focused on sibling relationship quality, after controlling for the parent-child relationship, and examined adolescents' self-regulation as a possible mechanism through which siblings exert their influence on adolescent outcomes.

\section{The Sibling Relationship}

Theoretically, the concept of sibling interactions providing a unique context in which behaviors may be developed is consistent with systems theory. This theory posits that every aspect of a system is inherently connected, or that each relational dyad works as a different aspect of the system, which influences every other aspect of the system (Broderick, 1995; Kim, McHale, Osgood, \& Crouter, 2006). The notion of siblings being uniquely important is also consistent with Bronfenbrenner's (1977) social ecological model. In this model, immediate family members (all residing in the child's microsystem) directly influence the development of the child, both uniquely and collectively, through day to day interactions. Taken together, all individuals within the immediate family system influence the child, and should thus be empirically studied simultaneously.

In addition to a theoretical justification for the importance of the sibling relationship, empirical research has established that the sibling relationship plays an important role in children's development and socialization (Parke \& Buriel, 2006). For example, children that have a positive sibling relationship are less likely to be victimized by peers (Lamarche et al., 2006), are more adaptive to disappointing peer relationships (East \& Rook, 1992), display greater emotional control in school situations (Stormshak, Bellanti, 
\& Bierman, 1996), are less likely to display externalizing behaviors (Kramer \& Kowal, 2005), and have better peer relationships (Kramer \& Gottman, 1992). Siblings also act as teachers, especially to younger siblings, which contributes to children's ability to take on the perspective of others (Maynard, 2002), and the need to be sensitive to the feelings and beliefs of others (Dunn, 1988). Beyond this, even when siblings experience a higher frequency of conflict, they are still likely to be prosocial toward each other. When this reciprocal prosociality is to a greater proportion than conflict, those same prosocial behaviors are likely to be expressed toward individuals other than the sibling (Dunn \& Munn, 1986). While these findings are important, many of these studies did not consider both the parent-child and the sibling relationship simultaneously, which is necessary when considering the family as a system.

\section{The Sibling Relationship in the Context of the Parent-Child Relationship}

It is widely accepted that parents have an impact on the development of both young children and adolescents (Burbach, Fox, \& Nicholson, 2004). Beyond parenting styles and discipline, research has found that the quality of the parent-child relationship is a consistent predictor of positive child outcomes, such as resiliency, higher self worth, and adjustment (Brennan, Le Brocque, \& Hammen, 2003; Magnus, Cowen, Wyman, Fagen, \& Work, 1999; Purdie, Carroll, \& Roche, 2004), as well as positive values and behaviors (Padilla-Walker \& Carlo, 2007). While it is well established that parenting is associated with positive child outcomes, less research has examined multiple familial relationships within the same model during adolescence. The studies that have examined sibling influences after controlling for parental factors suggest that sibling conflict and hostility is positively related to adolescents' negative adjustment (Stocker, Burwell, \& Briggs, 2002), antisocial behavior (Criss \& Shaw, 2005), and depression (Kim, McHale, Crouter, \& Osgood, 2007); while closeness or affection with a sibling is related to positive adjustment in children and adolescents (Kim et al., 2007; Pike et al., 2005). That being said, one study found that sibling relationships were not predictive of positive outcomes after controlling for parental factors, but they were predictive of negative outcomes (internalizing behaviors; Moser \& Jacob, 2002), while another study found that sibling closeness was a more salient influence on positive outcomes than was sibling conflict on negative outcomes (Pike et al., 2005). Clearly the sibling relationship is not always positive, but it is often emotionally intense, with high levels of both affection and hostility (Sheehan, Darlington, Noller, \& Feeney, 2004), which makes it important to examine different aspects of the sibling relationship when assessing its influence on adolescent outcomes.

Additional factors adding to the complexity of sibling relationships include age, birth order, space between siblings, and gender of the siblings. For example, older siblings, especially those with greater age differences, often serve as teachers of younger siblings, and are more effective at this role than are younger siblings (Tucker \& Updegraff, 2009; Youngblade \& Dunn, 1995). In turn, siblings closer in age engage in mutual exchanges in which siblings must learn to get along with each other, which provide opportunities for siblings to learn skills such as perspective taking and negotiation (Howe, Petrakos, Rinaldi, \& Lefebvre, 2004). In regard to gender, siblings of the same gender are more likely to be effective teaching and socializing agents of one another, and provide more support and encouragement than siblings of different genders (Branje et al., 2004; Tucker, Barber, \& Eccles, 1997), and older brothers are a more salient influence in promoting co-participation in deviant behaviors (Snyder et al., 2005). Gender and birth order have also been related to relational aggression among siblings, with sibling dyads having either an older sister or younger brother displaying higher levels of relational aggression (Stauffacher, \& DeHart, 2006). Thus, it is important for research on siblings to examine these complex dynamics of the sibling relationship to more clearly understand the unique role siblings have on adolescent development.

\section{Self Regulation as a Mediator}

While these findings are important in establishing the unique importance of the sibling relationship, little is known about the mechanisms through which siblings exert their influences on one another during adolescence. It has been hypothesized that siblings provide a unique context in which children can practice skills and behaviors learned elsewhere, and that by doing this, siblings can either reinforce or discourage those same behaviors and skills (Parke \& Buriel, 2006). For example, as a child learns to selfregulate with the help of a parent, having a positive sibling relationship provides practical situations wherein parents can work together with children to teach important skills. Sibling relationships are generally high conflict in middle childhood and early adolescence (Brody, 2004), providing parents with frequent opportunities to scaffold children's emotional development, which might not be as common without sibling interaction. Because siblings spend more time interacting with each other than they do with their parents during adolescence (Larson \& Richards, 1994), sibling relationships may be key for the practice and development of emotional and prosocial skills, as well as conflict resolution (Dunn \& Munn, 1986; Parke \& Buriel, 2006). Indeed, Volling and colleagues (2002) looked at behavioral regulation among preschoolers and found that sibling relationship quality was positively related to self-regulation, although the parent-child relationship was not taken into account. However, we know little about the unique and direct role of the sibling relationship in promoting internal skills, such as self-regulation, during adolescence. Although few studies have examined self-regulation as a mediator during adolescence, there is a substantial body of literature examining direct links between self-regulation and adolescent outcomes such as prosocial behavior, aggression (Purdie et al., 2004), and internalizing and externalizing behaviors (Eiden, Edwards, \& Leonard, 2007). Thus, the current 
study sought to understand whether self-regulation, or the ability to choose, initiate and carry out how one will think, feel, and act (Grolnick \& Farkas, 2002), mediated the relation between sibling relationship quality and adolescents' positive and negative behaviors, even after controlling for the quality of the parent-child relationship.

\section{The Current Study}

Based on a well-established body of literature suggesting that parents influence the development of self-regulation (e.g., Purdie et al., 2004), and that self-regulation is related to positive outcomes (Eiden et al., 2007), we explored (from the strength of a longitudinal design) whether the sibling relationship would also be positively related to both selfregulation and positive outcomes, and negatively related to negative outcomes. Considering that sibling relationships provide a unique influence on the family system (Kramer \& Kowal, 2005; Updegraff et al., 2005), we expected that the relations between sibling relationship quality and outcome variables would remain significant after controlling for the parent-child relationship. Given research suggesting that positive aspects of sibling relationships are more salient than negative aspects (Pike et al., 2005), we hypothesized that sibling affection would be positively related to adolescents' prosocial behavior and negatively related to externalizing and internalizing behaviors. However, given research suggesting that sibling conflict is also related to adolescent outcomes (Criss \& Shaw, 2005; Kim et al., 2007), we examined whether sibling hostility would be negatively related to prosocial behavior and positively related to externalizing and internalizing behaviors. In addition, because few studies have examined the differential impact of sibling relationships as a function of family structure, we sought to understand whether our model functioned differently for single- vs. two-parent families. It is possible that siblings may be more important for single-parent families, especially if siblings are seen as a source of support when resources are limited (Zukow-Goldring, 2002) or when parental conflict is high after a divorce (e.g., Abbey \& Dallos, 2004). However, siblings who by necessity act as caregivers might not serve the same function in regard to the promotion of self-regulation and behavioral outcomes as do siblings who have a more egalitarian relationship, and siblings may experience lower quality relationships if they are separated or in high conflict environments after a parental divorce (Riggio, 2001).

\section{Method}

\section{Participants}

The participants for this study were taken from Time 1 and Time 2 of the Flourishing Families Project (FFP). The FFP is an ongoing, longitudinal study of inner family life involving families with a child between the ages of 10 and 14 at Time 1 ( $M$ age of child $=11.29, S D=1.01,51 \%$ female). At Time 1, this study consisted of 500 (163 single parent and 337 two-parent) families, 96\% of whom had complete data for Time $2(N=478,154$ single parent and 324 two-parent families). At Time 2, 42 children in twoparent families and 50 children in single-parent families were only children (making them ineligible for this study), resulting in 282 two-parent and 113 single- parent families who were participants in the current study. Table 1 contains detailed demographic information in regard to ethnicity, income, number of children, and parent education at both time points.

In terms of descriptive characteristics of the siblings involved in this study, $50.4 \%$ of sibs in two-parent families were female $(54.9 \%$ in single parent families). In two-parent families the mean age for siblings was $11.10(S D=1.9)$, and $51.8 \%$ of the sibs were older than the target child $(M=$ 12.65, $S D=4.45$ in single-parent families, with $61.1 \%$ older than the target child). The mean number of years between the target child and the target sibling was 2.95 $(S D=1.52)$ in two- parent families and $3.55(S D=2.60)$ in single-parent families. Regarding birth order of the target children for two- and single-parent families, respectively, $43.3 \% / 36.0 \%$ were firstborn, $46.5 \% / 51.8 \%$ were second, $6.0 \% / 9.6 \%$ were third, $3.9 \% / 0.9 \%$ were fourth, and $0.4 \%$ $1.8 \%$ were fifth.

\section{Procedure}

Participant families for the FFP were selected from a large northwestern city and were interviewed during the first 8 months of 2007 for Time 1, and $\sim 1$ year later for Time 2 . At Time 1, families were primarily recruited using a purchased national telephone survey database (Polk Directories/InfoUSA). This database claimed to contain 82 million households across the United States and had detailed information about each household, including presence and age of children. Families identified using the Polk Directory were randomly selected from targeted census tracts that mirrored the socio-economic and racial stratification of reports of local school districts. All families with a child between the ages of 10 and 14 living within target census tracts were deemed eligible to participate. Of the 692 eligible families contacted, 423 agreed to participate, resulting in a $61 \%$ response rate. However, the Polk Directory national database was generated using telephone, magazine, and internet subscription reports; so families of lower socioeconomic status were under-represented. Therefore, in an attempt to more closely mirror the demographics of the local area, a limited number of families were recruited into the study through other means (e.g., referral, fliers; $n=77$, $15 \%$ ). By broadening our approach, we were able to significantly increase the socio-economic and ethnic diversity of the sample. The most frequent reasons cited by families for not wanting to participate in the study (at both Time 1 and Time 2) were lack of time and concerns about privacy. It is important to note that there were very few missing data at either time point. As interviewers collected each segment of the in-home interview, questionnaires were screened for missing answers and double marking. Full Information Maximum Likelihood was used via AMOSs data imputation program to deal with missing values where necessary. 
Table 1

Demographic Characteristics of Sample ( $N=395$ Families; 282 Two Parent Families, 113 Single Parent Families)

\begin{tabular}{|c|c|c|c|c|c|c|c|}
\hline & \multicolumn{4}{|c|}{ Two parent families } & \multicolumn{3}{|c|}{ Single parent families } \\
\hline & $\begin{array}{l}\text { Fathers } \\
(n=282)\end{array}$ & $\begin{array}{l}\text { Mothers } \\
(n=282)\end{array}$ & $\begin{array}{l}\text { Daughters } \\
(n=142)\end{array}$ & $\begin{array}{c}\text { Sons } \\
(n=140)\end{array}$ & $\begin{array}{l}\text { Mothers } \\
(n=113)\end{array}$ & $\begin{array}{l}\text { Daughters } \\
(n=62)\end{array}$ & $\begin{array}{c}\text { Sons } \\
(n=51)\end{array}$ \\
\hline \multirow{2}{*}{$\begin{array}{l}\text { Age at Time } 2 \\
\text { Number of children in family }\end{array}$} & $46.47(6.03)$ & $44.37(5.43)$ & $12.20(1.04)$ & $12.28(1.03)$ & $42.90(7.85)$ & $12.38(1.21)$ & $12.72(1.23)$ \\
\hline & \multicolumn{4}{|c|}{$\begin{array}{r}2.53 \text { (.83) Range } 2-7 \\
\text { Percentages }\end{array}$} & \multicolumn{3}{|c|}{$2.47(.78)$ Range 2-6 } \\
\hline \multicolumn{8}{|l|}{ Race } \\
\hline White & $86.1 \%$ & $83.9 \%$ & $78.0 \%$ & $80.0 \%$ & $54.0 \%$ & $43.5 \%$ & $43.1 \%$ \\
\hline African American & $5.6 \%$ & $4.5 \%$ & $4.5 \%$ & $3.0 \%$ & $38.1 \%$ & $33.9 \%$ & $39.2 \%$ \\
\hline Hispanic & $0.7 \%$ & $2.2 \%$ & $1.9 \%$ & $1.5 \%$ & $0.9 \%$ & $1.6 \%$ & $2.0 \%$ \\
\hline Asian American & $2.2 \%$ & $4.5 \%$ & $4.5 \%$ & $3.7 \%$ & $1.8 \%$ & $6.5 \%$ & $0 \%$ \\
\hline Other & $2.2 \%$ & $1.5 \%$ & $0.0 \%$ & $1.5 \%$ & $1.8 \%$ & $1.6 \%$ & $0 \%$ \\
\hline Multiethnic & $3.0 \%$ & $3.4 \%$ & $11.1 \%$ & $10.4 \%$ & $3.5 \%$ & $12.9 \%$ & $15.7 \%$ \\
\hline \multicolumn{8}{|l|}{ Parents' education } \\
\hline Less than high school & $0 \%$ & $1.5 \%$ & - & - & $8.8 \%$ & - & - \\
\hline High school & $5.6 \%$ & $4.5 \%$ & - & - & $15.9 \%$ & - & - \\
\hline Some college & $24.4 \%$ & $23.9 \%$ & - & - & $39.0 \%$ & - & - \\
\hline Bachelors & $40.4 \%$ & $42.4 \%$ & - & - & $23.0 \%$ & - & - \\
\hline Grad/professional & $29.6 \%$ & $27.7 \%$ & - & - & $13.3 \%$ & - & - \\
\hline Household income & \multicolumn{2}{|c|}{ Time 1} & \multicolumn{2}{|c|}{ Time 2} & \multicolumn{2}{|c|}{ Time 1} & Time 2 \\
\hline Under $\$ 19,999$ & \multicolumn{2}{|c|}{$4.4 \%$} & \multicolumn{2}{|c|}{$0.4 \%$} & \multicolumn{2}{|c|}{$35.3 \%$} & $23.0 \%$ \\
\hline$\$ 20,000-39,999$ & \multicolumn{2}{|c|}{$8.8 \%$} & \multicolumn{2}{|c|}{$1.8 \%$} & \multicolumn{2}{|c|}{$31.4 \%$} & $28.3 \%$ \\
\hline$\$ 40,000-59,999$ & \multicolumn{2}{|c|}{$16.4 \%$} & \multicolumn{2}{|c|}{$8.2 \%$} & \multicolumn{2}{|c|}{$18.0 \%$} & $26.5 \%$ \\
\hline$\$ 60,000-79,999$ & \multicolumn{2}{|c|}{$27.4 \%$} & \multicolumn{2}{|c|}{$15.6 \%$} & \multicolumn{2}{|c|}{$8.1 \%$} & $9.7 \%$ \\
\hline$\$ 75,000-99,999$ & \multicolumn{2}{|c|}{$11.5 \%$} & \multicolumn{2}{|c|}{$16.3 \%$} & \multicolumn{2}{|c|}{$5.4 \%$} & $7.1 \%$ \\
\hline$\$ 100,000-139,999$ & & & 31.4 & & $0.9 \%$ & & $2.7 \%$ \\
\hline$\$ 140,000+$ & & & 25.2 & & $0.9 \%$ & & $2.7 \%$ \\
\hline Missing & & & 1.1 & & $0.0 \%$ & & $0.0 \%$ \\
\hline
\end{tabular}

\section{Measures}

At Time 1 adolescents and parents completed measures of their relationship quality and adolescents completed a measure of their relationship with a sibling (only mother and child reported in single-parent families). At Times 1 and 2 , mothers, fathers, and adolescents reported on the adolescent's self-regulation and externalizing behaviors (only mother and child reported in single-parent families). At Times 1 and 2, adolescents reported on their own prosocial and internalizing behaviors.

Parent-child relationship quality. Parent-child relationship quality was assessed at Time 1 using 9 items from the Social Connectedness Scale (Lee, Draper, \& Lee, 2001) and 8 items from the Inventory of Parent and Peer Attachment (Armsden \& Greenberg, 1987). For connectedness, parents responded on a Likert scale ranging from 1 (disagree) to 6 (agree; e.g., "I feel close to my child"). For attachment, adolescents responded on a scale of 1 (strongly disagree) to 5 (strongly agree; e.g., "My parent respects my feelings," "I do not think I can depend on my parent"). Both measures have been used previously on adolescent samples, and show adequate validity and reliability with this age group (Day \& Padilla-Walker, 2009). Mother-child relationship quality was created using child-report of attachment $(\alpha=.71$, factor loading $=.84 / .83$; values after slash are for singleparent families) and mother-report of connectedness $(\alpha=$
.72 , factor loading $=.83 / .81)$. Father-child relationship quality was created in two-parent families by using child's report of attachment to father $(\alpha=.74$, factor loading $=$ $.81)$ and father-report of connectedness to child $(\alpha=.75$, factor loading $=.86$ ).

Sibling relationship quality. The target child's relationship with one sibling (closest to the target child in age) was assessed at Time 1 using two subscales (hostility, $\alpha=.83$; and affection, $\alpha=.81$ ) of the Sibling Relationship Inventory (Stocker \& McHale, 1992), modified slightly to be more appropriate for adolescents. Respondents answered how often each item occurred on a 5-point Likert scale ranging from 1 (never) to 5 (always). Sample items from each subscale include, "Start fights or cause trouble for each other" and "Share secrets with one another."

Self regulation. The adolescent's self-regulation was assessed at Time 1 and 2 from mother-, father-, and childreports of behavioral, emotional, and cognitive selfregulation using a revised 13 item version of the Novak and Clayton (2001) self-regulation measure. This measure has been used with adolescents and has displayed adequate validity and reliability (Padilla-Walker \& Christensen, in press). Individuals responded to how much they agreed or disagreed with statements such as "I/my child get(s) distracted by little things," "I/my child have (has) difficulty controlling his/her temper," "Once I/my child have a goal, 
I/he/she makes a plan how to reach it." Responses ranged from 1 (never true) to 5 (always true), with higher scores representing higher ability to self-regulate. In the current study, mother- $(\alpha=.88$, factor loading $=.86 / .82)$, father$(\alpha=.86$, factor loading $=.85)$, and child- $(\alpha=.81$, factor loading $=.72 / .83$ ) reports were used to create a latent variable representing self-regulation.

Prosocial behavior. Adolescents' prosocial behavior was measured at Time 1 and 2 using the Kindness and Generosity subscale of the Values in Action Inventory of Strengths (Peterson \& Seligman, 2004), which has been used extensively with adolescent samples and has shown adequate reliability and validity (e.g., Padilla-Walker \& Carlo, 2007). Sample items included "I help others even if it is not easy for me" and "I enjoy doing small favors for others." Adolescent answered these items on a Likert scale ranging from 1 (not like me at all) to 5 (very much like me). The individual scale items were used to create latent variables at both time points.

Externalizing and internalizing behavior. Externalizing and internalizing behaviors were assessed at Time 1 and 2 from a measure taken from the Youth and Family project (Barber, Stolz, \& Olsen, \& Maughn, 2005) assessing antisocial behavior (9 items) and depression/anxiety (13 items). Sample items for externalizing include, "I lie or cheat" and "I steal things from other places than home;" and for internalizing include, "I am unhappy, sad, or depressed" and "I feel that no one loves me." Participants answered these items in regard to the adolescent's behavior on a scale ranging from 0 (not true) to 2 (very true or often true). For externalizing behaviors, mother- $(\alpha=.70$, factor loading $=$ $.85 / .82)$, father- $(\alpha=.71$, factor loading $=.84)$, and child$(\alpha=.69$, factor loading $=.62 / .86)$ reports were used to create Time 1 and Time 2 latent variables. Because parents did not complete internalizing questions, the child's answers to individual items were used to create latent variables of internalizing at Time 1 and 2 .

\section{Results}

\section{Descriptive Statistics and Correlations}

Table 2 shows the means and standard deviations for all observed variables. In terms of self regulation, both boys and girls in single-parent families saw themselves as less self regulated than those in two-parent families $(p<.05)$. In both single- and two-parent families, girls saw themselves as more prosocial than boys. Mothers (of both girls and boys), girls, and boys reported more externalizing behavior in single-parent families $(1.81,2.55,11.18$, and 11.06) than in two-parent families $(.35, .79,9.81$, and 10.27). Both girls and boys in two-parent families $(28.27,26.14)$ reported higher internalizing behaviors than those in single-parent families $(18.44,15.90)$. Table 3 reports correlations between latent variables. Most notably, sibling affection (.38) and hostility $(-.18)$ were significantly correlated with adolescents' self-regulation, prosocial, and externalizing behavior $(.29, .15,-.23)$; and sibling hostility was significantly correlated with self-regulation and internalizing behavior $(-.23, .27)$.

\section{Self Regulation as a Mediator Between Sibling Relationship Quality and Adolescents' Prosocial, Externalizing, and Internalizing Behaviors}

Using multiple group comparison in AMOS 16 (Arbuckle, 2007; allowing for different path diagrams for dif-

Table 2

Means, SDs, Alpha Coefficients, and Factor Loadings for Variables ( $N=395$ Families; 282 Two Parent Families-282 Fathers, 282 Mothers, 142 Daughters, 140 Sons, 113 Single Parent Families-113 Mothers, 62 Daughters, 51 Sons)

\begin{tabular}{|c|c|c|c|c|c|c|}
\hline \multirow[b]{3}{*}{ Variables } & \multicolumn{2}{|c|}{ Two-parent $(n=282)$} & \multicolumn{2}{|c|}{ Single-parent $(n=113)$} & \multirow[b]{3}{*}{$\alpha$} & \multirow[b]{3}{*}{ Factor loading } \\
\hline & $\begin{array}{l}\text { Daughters } \\
(n=142)\end{array}$ & $\begin{array}{c}\text { Sons } \\
(n=140)\end{array}$ & $\begin{array}{c}\text { Daughters } \\
(n=62)\end{array}$ & $\begin{array}{c}\text { Sons } \\
(n=51)\end{array}$ & & \\
\hline & $\bar{X}(S D)$ & $\bar{X}(S D)$ & $\bar{X}(S D)$ & $\bar{X}(S D)$ & & \\
\hline T1 Attachment to father (CR) & $33.59(4.33)$ & $33.36(3.57)$ & $32.24(4.56)$ & $32.37(5.32)$ & .71 & $.84 / .83$ \\
\hline T1 Connection (MR) & $44.56(5.14)$ & $44.57(4.88)$ & $43.10(6.69)$ & $43.80(4.92)$ & .72 & $.83 / .81$ \\
\hline T1 Attachment to father (CR) & $33.17(4.29)$ & $32.96(3.95)$ & - & - & .74 & $.86 /-$ \\
\hline T1 Connection (FR) & $43.29(6.33)$ & $42.46(5.98)$ & - & - & .75 & $.81 /-$ \\
\hline T1 Sibling affection (CR) & $18.74(5.28)$ & $18.04(4.71)$ & $18.98(6.50)$ & $16.94^{\mathrm{a}}(5.47)$ & .81 & N/A \\
\hline T1 Sibling hostility (CR) & $13.20(3.76)$ & $13.35(3.72)$ & $12.47(5.46)$ & $12.65(4.87)$ & .83 & N/A \\
\hline \multicolumn{7}{|l|}{ T2 Self regulation } \\
\hline Mother's view of child & $38.63(6.05)$ & $35.62(6.70)$ & $36.97(7.59)$ & $34.64(8.02)$ & $\begin{array}{l}.81 \\
.88\end{array}$ & $\begin{array}{l}.72 / .83 \\
.86 / .82\end{array}$ \\
\hline Father's view of child & $35.49(5.48)$ & $33.41(5.65)$ & - & - & .86 & $.85 /-$ \\
\hline T2 Prosocial behavior (CR) & $28.27(6.33)$ & $26.14(6.16)$ & $27.21(7.21)$ & $22.80^{\mathrm{a}}(6.14)$ & .91 & $.57-.83 / .65-.79$ \\
\hline \multicolumn{7}{|l|}{ T2 Externalizing behavior } \\
\hline Child's self report & $9.81(1.30)$ & $10.27(1.60)$ & $11.18^{\mathrm{b}}(2.36)$ & $11.06^{\mathrm{b}}(2.50)$ & .69 & $.62 / .86$ \\
\hline Mother's view of child & $.35(.87)$ & $.79(1.07)$ & $1.81^{\mathrm{a}}(2.75)$ & $2.55^{\mathrm{a}}(2.46)$ & .70 & $.85 / .82$ \\
\hline Father's view of child & $.52(1.10)$ & $.91(1.23)$ & - & - & .71 & $.84 /-$ \\
\hline T2 Internalizing behavior (CR) & $28.27(6.33)$ & $26.14(6.16)$ & $18.44^{\mathrm{a}}(4.87)$ & $15.90^{\mathrm{a}}(3.32)$ & .88 & $.54-.87 / .53-.82$ \\
\hline
\end{tabular}

Note. Mean values represent means of summed scales.

${ }^{a}$ Significantly different at .05 level from the other three. ${ }^{\text {b }}$ Significantly different at .05 level from sons/daughters in two parent families but not from each other. 
Table 3

Correlations Among Latent Variables

\begin{tabular}{|c|c|c|c|c|c|c|c|c|}
\hline & 1 & 2 & 3 & 4 & 5 & 6 & 7 & 8 \\
\hline 1. Mother-child relationship quality T1 & 1.00 & & & & & & & \\
\hline 2. Father-child relationship quality $\mathrm{T} 1$ & $.78^{\text {**** }}$ & 1.00 & & & & & & \\
\hline 3. Sibling affection & $.21^{* * *}$ & .10 & 1.00 & & & & & \\
\hline 4. Sibling hostility & $-.18^{*}$ & $-.22^{* *}$ & $-.28^{* * *}$ & 1.00 & & & & \\
\hline 5. Child self regulation $\mathrm{T} 2$ & $.19^{*}$ & .11 & $.29^{* * * *}$ & $-.23^{* *}$ & 1.00 & & & \\
\hline 6. Child prosocial behavior $\mathrm{T} 2$ & $.29^{* * * *}$ & $.31^{* * * * *}$ & $.38^{* * * *}$ & $-.18^{*}$ & $.39^{* * * * *}$ & 1.00 & & \\
\hline 7. Child externalizing behavior $\mathrm{T} 2$ & $-.28^{* * * *}$ & $-.26^{* * * *}$ & $-.23^{* * *}$ & $.15^{*}$ & $-.31^{* * * *}$ & $-.15^{*}$ & 1.00 & \\
\hline 8. Child internalizing behavior $\mathrm{T} 2$ & $-.17^{*}$ & $-.13^{*}$ & -.12 & $.27^{* * * *}$ & $-.33^{* * * *}$ & -.07 & $.17^{*}$ & 1.00 \\
\hline
\end{tabular}

${ }^{*} p<.05 . \quad{ }^{* *} p<.01 . \quad{ }^{* * *} p<.001$.

ferent groups so we could keep father-reports for self regulation and externalizing), we compared a fully constrained model (with all structural paths equal for two- and singleparent families) to a fully unconstrained model (in which all structural paths were freely estimated for both two- and single-parent families). Child self-regulation, prosocial, externalizing, and internalizing behaviors at Time 1 were all entered into the model as control variables, with paths to their corresponding Time 2 variables. Their standardized betas were all statistically significant at the .001 level for both single- and two-parent families (T1 self regulation to $\mathrm{T} 2$ self regulation $=.83 / .78 ; \mathrm{T} 1$ prosocial to $\mathrm{T} 2$ prosocial $=$ $.69 / .62 ; \mathrm{T} 1$ externalizing to $\mathrm{T} 2$ externalizing $=.73 / .79 ; \mathrm{T} 1$ internalizing to T2 internalizing $=.54 / .69)$. Gender of target child and sibling, child race, age, birth order, number of children in family, spacing in years between target child and sibling, and household income were used as control variables by examining paths to all Time 2 variables.

Results showed that race of child (to self-regulation $\beta=$ $.03 / .04$; to prosocial $\beta=.04 / .06$; to externalizing $\beta=$ $.01 / .03$; to internalizing $\beta=.02 / .06$ ); birth order (to self regulation $\beta=.01 / .02$; to prosocial $\beta=.07 / .05$; to externalizing $\beta=.04 / .04$; to internalizing $\beta=-.01 / .02$ ); number of children (to self regulation $\beta=.06 / .05$; to prosocial $\beta=.02 / .00$; to externalizing $\beta=-.06 /-.02$; to internalizing $\beta=.05 / .03$ ); years between siblings (to self regulation $\beta=-.05 /-.01$; to prosocial $\beta=-.03 /-.01$; to externalizing $\beta=-.06 /-.04$; to internalizing $\beta=.01 / .01)$; and household income (to self regulation $\beta=.02 / .03$; to prosocial $\beta=.03 / .05$; to internalizing $\beta=.01 / .03$ ), were not significantly related to adolescent outcomes, so these paths are not shown in the final model.

The Chi-square value for the fully constrained model was $107.19(d f=94, p=.16, \mathrm{CFI}=.980, \mathrm{RMSEA}=.003)$, and the $\chi^{2}$ value for the unconstrained model was 144.94 $(d f=119, p=.054, \mathrm{CFI}=.970, \mathrm{RMSEA}=.03)$, which indicates good fit. To determine if the fully constrained and fully unconstrained models were significantly different from each other, the Chi-square difference test was used, which showed that the models were significantly different (difference between the two values was 37.75; difference between the degrees of freedom was 25; critical value needed at .05 level was 37.652). We then freed equality constraints one at a time and conducted nested, chi-square difference tests. The best fit was a model that allowed the following paths to be unconstrained: mother-child relationship quality at Time 1 to adolescent self regulation and prosocial behavior at Time 2, child's gender to prosocial and externalizing behavior at Time 2, sibling affection to adolescent self regulation and prosocial behavior at Time 2, and sibling hostility to internalizing behavior at Time 2 .

Results suggested good model fit for this final model, $\chi^{2}=104.76, d f=96, p=.25, \mathrm{CFI}=.991, \mathrm{RMSEA}=.030$. As shown in Figure 1, the paths between child gender and child self regulation were statistically significant for both two- and single-parent families $(\beta=.19, p<.01 ; \beta=.26$, $p<.001)$, with girls exhibiting more self regulation than boys. The paths from child gender to prosocial behavior and externalizing were significant in two-parent families $(\beta=$ $.14, p<.05$ and $\beta=-.15, p<.05)$ but not in single-parent families. Mother-child relationship quality at Time 1 was positively related to prosocial behavior at Time 2 for twoparent families $(\beta=.16, p<.05)$ but not for single-parent families, and negatively related to child externalizing behavior at Time 2 for both two- $(\beta=-.25, p<.001)$ and single-parent families $(\beta=-.14, p<.05)$. Father-child relationship quality was positively related to prosocial behavior at Time $2(\beta=.15, p<.05)$ and negatively related to externalizing behaviors at Time $2(\beta=-.21, p<.01)$. Sibling affection was positively related to prosocial behavior in both two- $(\beta=.32, p<.001)$ and single-parent families $(\beta=.14, p<.05)$. Sibling affection was also negatively related to child externalizing behavior at Time 2 for two- $(\beta=-.13, p<.05)$ and single-parent families $(\beta=-.21, p<.01)$. The only exogenous variable that was significantly related to child internalizing behavior at Time 2 was sibling hostility $(\beta=.12, p<.05)$ for two-parent families only. Child self regulation at Time 2 was positively related to child prosocial behavior at Time 2 in both twoand single-parent families $(\beta=.25, p<.001 ; \beta=.20, p<$ $.01)$, negatively related to child externalizing behavior at Time $2(\beta=-.22, p<.01 ; \beta=-.25, p<.001)$, and negatively related to internalizing behavior at Time $2(\beta=$ $-.29, p<.001 ; \beta=-.31, p<.001)$, even after controlling for these outcomes at Time 1 . The paths from gender of target sibling to internalizing behavior were significant in both two- and single-parent families $(\beta=-.13, p<.05$; $\beta=-.12, p<.05)$ with those children who had a female sibling exhibiting less internalizing behavior.

To determine whether adolescents' self regulation was a 


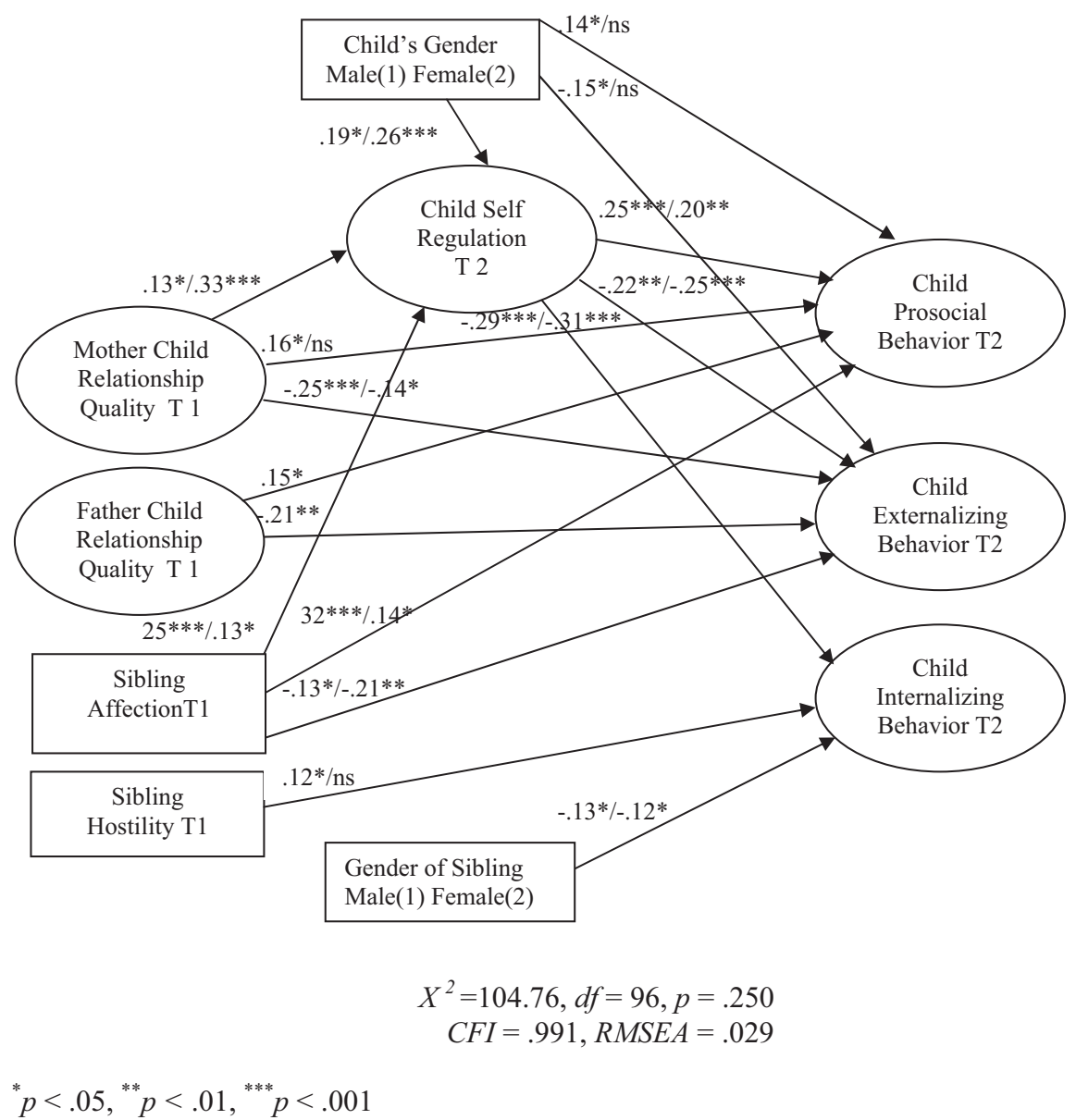

Figure 1. Self-Regulation as a Mediator between Sibling Relationship Quality and Adolescents' Prosocial, Externalizing, and Internalizing Behaviors $(n=282$ two-parent families, 113 singleparent families.

Note. Standardized betas for single parent families follow the slash. Statistically nonsignificant paths are not shown.

significant mediator, Sobel tests were calculated using Mackinnon et al.'s method (Mackinnon et al., 2002). In both the two-parent and single-parent models, all of the Sobel tests for mother-child relational quality through self regulation to child prosocial, externalizing, and internalizing were significant $(z=2.67,-2.59$, and -2.68 for twoparent, all $p<.01 ; z=2.14, p<.05 ;-2.38, p<.05$; $-2.22, p<.05$ for single-parent). Likewise, the indirect effects from sibling affection through child self regulation to prosocial, externalizing, and internalizing were all significant in both models $(z=5.13, p<.001 ;-2.47, p<.01$; $-5.14, p<.001$ for two-parent; $4.83,-3.47,-3.53$ for single-parents, all $p<.001$.$) . The indirect paths from$ gender of child through self regulation to prosocial, externalizing, and internalizing were all significant in both models $(z=3.61, p<.001 ;-2.22, p<.05 ;-3.60$, $p<.001$ for two-parent; $z=2.59,-4.83,-4.78$, for single-parent, all $p<.001)$. Taken together with direct paths, it can be concluded that adolescents' self regulation partially mediated the relations between gender of child, mother-child relational quality, and sibling affection; and adolescents' prosocial, externalizing, and internalizing behaviors.

\section{Discussion}

The current study sought to examine the role of selfregulation as a mediator between sibling affection and hostility, and adolescents' positive and negative outcomes, after controlling for the parent-child relationship. We hypothesized that sibling relationship quality would be positively associated with adolescents' prosocial behavior and negatively associated with externalizing and internalizing behavior. We also hypothesized that self-regulation would act as a mediating variable between relationship quality and adolescent outcomes. Findings generally supported these hypotheses for both two-parent and single-parent families, although sibling relationship quality tended to be more strongly related to outcomes for two-parent families. 


\section{The Sibling Relationship}

The current study found sibling affection to be directly and positively related to prosocial behaviors, and negatively related to externalizing behaviors; and sibling hostility to be positively and directly related to internalizing behaviors. This suggests that siblings influence both positive and negative adolescent outcomes, although sibling affection was more consistently related to outcomes than was sibling hostility, which is consistent with past research (e.g., Pike et al., 2005). It is possible that siblings promote the development of prosocial behavior and the avoidance of externalizing and internalizing behavior because siblings share a horizontal relationship because of similarity in age (as opposed to the vertical relationship shared with parents), which may partially account for the direct and robust path from sibling relationship quality to adolescents' prosocial behavior (the path was twice as large as that from motherchild relationship quality to prosocial behavior for twoparent families). In other words, because sibling relationships in the United States are often not as hierarchical as are parent-child relationships, they likely foster a dynamic more similar to peer relationships, wherein adolescents feel free to express themselves and practice interactions that lead to empathy and perspective taking, both of which are strong predictors of prosocial behavior. In addition, sibling hostility was the only aspect of relationship quality related to internalizing behaviors (for two-parent families only), suggesting that perceived hostility from a sibling may be even more salient than parenting influences, although parental hostility was not assessed in the current study. Further, having a sister was a protection against internalizing behaviors, perhaps because of higher levels of communication and/or caregiving by sisters (Zukow-Goldring, 2002).

\section{Self Regulation as a Partial Mediator}

Although direct paths from sibling relationship quality to behavioral outcomes existed, findings from the current study also suggested that the sibling relationship was indirectly related to adolescents' positive and negative behaviors via adolescents' self-regulation. Research suggests that sibling relationships promote children's ability to take the perspective of (Maynard, 2002) and be empathic toward others (Dunn, 1988), which suggests that these dispositional qualities may be one mechanism through which siblings exert their influence on positive development. The current findings add to existing research by suggesting that sibling affection might also play a unique role in promoting adolescents' self-regulation. Throughout childhood, sibling interactions (both positive and negative) provide opportunities for children to learn about sharing, emotional control, empathy, and conflict resolution; oftentimes before these skills can be practiced through interaction with peers. This may help set the early groundwork needed to promote positive development, and may continue to be beneficial throughout adolescence. Given that findings held after controlling for outcomes at Time 1 , it can also be suggested that even during adolescence, when parental scaffolding of sibling interactions is likely to be less frequent than it is during childhood, sibling affection is related to change in adolescents' self-regulation and behaviors over time. It is possible that siblings' encouragement of one another and mutual conflict resolution during early adolescence provide a unique platform to practice self-regulatory skills, over and above the opportunities provided by the parent-child relationship. Although sibling interactions during adolescence are quite unique from those that occur during early childhood, these findings suggest that, much like the parent-child relationship, a positive sibling relationship may act as a training ground for self-regulation, which in turn is an impetus to be more prosocial, and a deterrent from negative behaviors.

\section{Sibling Relationships as a Function of Family Structure}

There is a dearth of research examining the differences in sibling relationships as a function of family structure, so the current study adds to this gap by suggesting that paths from sibling affection and hostility to self-regulation and behavioral outcomes were generally stronger for adolescents from two-parent families than for those from single-parent families. Although only about half of single-parent families in the current study had experienced a divorce, research on sibling relationships after divorce is mixed, with some suggesting relationships improve as siblings support one another through a difficult time (Abbey \& Dallos, 2004; Bush \& Ehrenberg, 2003); and others suggesting that relationship quality decreases (Riggio, 2001), perhaps because of the modeling of conflict or the intense emotions experienced after parental divorce (Sheenhan et al., 2004). Another possibility to explain the current finding for single-parent families, regardless of the reason for single-status, is that siblings from single-parent families may be forced into a caregiver role that acts more like a parent-child relationship than a sibling relationship (Zukow-Goldring, 2002), and this type of hierarchical or vertical sibling relationship may not provide frequent opportunities for practicing self-regulation and promoting positive behaviors in the same ways that typically egalitarian or horizontal sibling relationships do. Future research is clearly needed on the role of sibling relationship quality as a function of family structure.

\section{Limitations and Conclusions}

The current study was not without limitations. First, our study relied solely on self-reports of sibling relationships, which represents only one perception and may not be representative of reality. Thus, future research should continue to examine both self- and sibling-reports of the relationship. Further, although most variables were measured from multiple informants, future research should increase ecological validity by not relying solely on questionnaire data. Finally, although the longitudinal design was a strength of the current study, there was a relatively short period of time between waves ( 1 year), and future research should continue to examine the influence of the sibling relationship over longer periods of time. 
Despite these limitations, the current study adds to existing literature in at least three important ways. First, findings support a unique, longitudinal relation between sibling affection and hostility, and adolescents' prosocial, externalizing, and internalizing behaviors, even after controlling for the quality of the parent-child relationship. Second, findings suggest that self regulation partially mediates the relation between sibling relationship quality and behavioral outcomes, supporting the utility of continuing to examine adolescents' dispositional characteristics as potential explanations of the means through which sibling relationships influence adolescent development. And third, findings suggest that sibling affection and hostility are more strongly related to outcomes for adolescents in two-parent than single-parent families. These findings have important implications for prevention or intervention programs focusing on family approaches to fostering positive development in children, and suggest utility in focusing on the unique nature of the sibling relationship.

\section{References}

Abbey, C., \& Dallos, R. (2004). The experience of the impact of divorce on sibling relationships: A qualitative study. Clinical Child Psychology and Psychiatry, 9, 241-259.

Arbuckle, J. L. (2007). Amos 16.0 user's guide. Chicago, IL: SPSS, Amos Development Corporation.

Armsden, G. C., \& Greenberg, M. T. (1987). The inventory of parent and peer attachment: Individual differences and their relationship to psychological well-being in adolescence. Journal of Youth and Adolescence, 16, 427-454.

Barber, B. K., Stolz, H. E., Olsen, J. A., \& Maughn, S. L. (2005). Parental support, psychological control, and behavioral control: Assessing relevance across time, culture, and method. Monographs of the Society for Research in Child Development, 70.

Branje, S. J. T., van Lieshout, C. F. M., van Aken, M. A. G., \& Haselager, G. J. T. (2004). Perceived support in sibling relationships and adolescent adjustment. Journal of Child Psychology and Psychiatry, 45, 1385-1396.

Brennan, P. A., Le Brocque, R., \& Hammen, C. (2003). Maternal depression, parent-child relationships, and resilient Outcomes in adolescence. Journal of the American Academy of Child and Adolescent Psychiatry, 42, 1469-1477.

Broderick, C. B. (1995). Understanding family process: Basics of family systems theory. Thousand Oaks, CA: Sage Publications.

Brody, G. H. (2004). Siblings' direct and indirect contributions to child development. Current Directions in Psychological Science, 13, 124-126.

Bronfenbrenner, U. (1977). Toward an experimental ecology of human development. American Psychologist, 32, 513-531.

Burbach, A. D., Fox, R. A., \& Nicholson, B. C. (2004). Challenging behaviors in children: The father's role. The Journal of Genetic Psychology, 165, 169-183.

Bush, J. E., \& Ehrenberg, M. F. (2003). Young persons' perspectives on the influence of family transitions on sibling relationships: A qualitative exploration. Journal of Divorce and Remarriage, $39,1-35$.

Criss, M. M., \& Shaw, D. S. (2005). Sibling relationships as contexts for delinquency training in low-income families. Journal of Family Psychology, 19, 592-600.

Day, R. D., \& Padilla-Walker, L. M. (2009). Mother and father connectedness and involvement during early adolescence. Journal of Family Psychology, 23, 900-904.
Dunn, J. F. (1988). Sibling influences on child development. Journal of Child Psychology and Psychiatry, 29, 119-127.

Dunn, J. F., \& Munn, P. (1986). Siblings and the development of prosocial behaviour. International Journal of Behavioral Development, 9, 265-284.

East, P. L., \& Rook, K. S. (1992). Compensatory patterns of support among children's peer relationships: A test using school friends, nonschool friends, and siblings. Developmental Psychology, 28, 163-172.

Eiden, R. D., Edwards, E. P., \& Leonard, K. E. (2007). A conceptual model for the development of externalizing behavior problems among kindergarten children of alcoholic families: Role of parenting and children's self regulation. Developmental Psychology, 43, 1187-1201.

Grolnick, W. S., \& Farkas, M. (2002). Parenting and the development of children's self regulation. In M. H. Bornstein (Ed.), Handbook of parenting: Vol. 5, practical issues in parenting (2nd ed., pp. 89-110). Mahwah, NJ: Lawrence Erlbaum Associates.

Howe, N., Petrakos, H., Rinaldi, C. M., \& LeFebvre, R. (2004). "This is a bad dog, you know...": Constructing shared meaning during sibling pretend play. Child Development, 76, 783-794.

Kim, J. Y., McHale, S. M., Crouter, A. C., \& Osgood, D. W. (2007). Longitudinal linkages between sibling relationships and adjustment from middle childhood through adolescence. Developmental Psychology, 43, 960-973.

Kim, J. Y., McHale, S. M., Osgood, D. W., \& Crouter, A. C. (2006). Longitudinal course and family correlates of sibling relationships from childhood through adolescence. Child Development, 77, 1746-1761.

Kramer, L., \& Bank, L. (2005). Sibling relationship contributions to individual and family well-being: Introduction to the special issue. Journal of Family Psychology, 19, 483-485.

Kramer, L., \& Gottman, J. M. (1992). Becoming a sibling: With a little help from my friends. Developmental Psychology, 28, 685-699.

Kramer, L., \& Kowal, A. K. (2005). Sibling relationship quality from birth to adolescence: The enduring contribution of friends. Journal of Family Psychology, 19, 503-511.

Lamarche, V., Brendgen, M., Boivin, M., Vitaro, F., Perusse, D., \& Dionne, G. (2006). Do friendships and sibling relationships provide protection against peer victimization in a similar way? Social Development, 15, 373-393.

Larson, R., \& Richards, M. H. (1994). Divergent realities: The emotional lives of mothers, fathers, and adolescents. New York: NY: Basic Books

Lee, R. M., Draper, M., \& Lee, S. (2001). Social connectedness, dysfunctional interpersonal behaviors, and psychological distress: Testing a mediator model. Journal of Counseling Psychology, 48, 310-318.

MacKinnon, D. P., Lockwood, C. M., Hoffman, J. M., West, S. G., \& Sheets, V. (2002). A comparison of methods to test mediation and other intervening variable effects. Psychological Methods, 7 , 83-104.

Magnus, K. B., Cowen, E. L., Wyman, P. A., Fagen, D. B., \& Work, W. C. (1999). Parent-child relationship qualities and child adjustment in highly stressed urban black and white families Journal of Community Psychology, 27, 55-71.

Maynard, A. E. (2002). Cultural teaching: The development of teaching skills in Maya sibling interactions. Child Development, 73, 969-982.

Moser, R. P., \& Jacob, T. (2002). Parental and sibling effects in adolescent outcomes. Psychological Reports, 91, 463-479.

Novak, S. P., \& Clayton, R. R. (2001). The influence of school environment and self-regulation on transitions between stages of cigarette smoking: A multilevel analysis. Health Psychology, 20, 196-207. 
Padilla-Walker, L. M., \& Carlo, G. (2007). Personal values as a mediator between parent and peer expectations and adolescent behaviors. Journal of Family Psychology, 21, 538-541.

Padilla-Walker, L. M., \& Christensen, K. J. (in press). Empathy and self-regulation as mediators between parenting and adolescents' prosocial behaviors toward strangers, friends, and family. Journal of Research on Adolescence.

Parke, R. D., \& Buriel, R. (2006). Socialization in the family: Ethnic and ecological perspectives. In N. Eisenberg, W. Damon, \& R. Lerner (Eds.), Handbook of child psychology: Vol. 3, Social, emotional, and personality development (6th ed., pp 429-504). Hoboken, NJ: John Wiley and Sons.

Peterson, C., \& Seligman, M. E. P. (2004). Character strengths and virtues: A handbook and classification. Washington, DC: Oxford University Press.

Pike, A., Coldwell, J., \& Dunn, J. F. (2005). Sibling relationships in early/middle childhood: Links with individual adjustment. Journal of Family Psychology, 19, 523-532.

Purdie, N., Carroll, A., \& Roche, L. (2004). Parenting and adolescent self-regulation. Journal of Adolescence, 27, 663-676.

Riggio, H. R. (2001). Relations between parental divorce and the quality of adult sibling relationships. Journal of Divorce and Remarriage, 36, 67-82.

Sheehan, G., Darlington, Y., Noller, P., \& Feeney, J. (2004). Children's perceptions of their sibling relationships during parental separation and divorce. Journal of Divorce and Remarriage, 41, 69-94.

Snyder, J., Bank, L., \& Burraston, B. (2005). The consequences of antisocial behavior in older male siblings for younger brothers and sisters. Journal of Family Psychology, 19, 643-653.

Stauffacher, K., \& DeHart, G. B. (2006). Crossing social contexts: Relational aggression between siblings and friends during early and middle childhood. Applied Developmental Psychology, 27, 228-240.

Steinberg, L., \& Silk, J. S. (2002). Parenting adolescents. In M. H. Bornstein (Ed.), Handbook of parenting: Vol. 1: Children and parenting (2nd ed., pp. 103-133). Mahwah, NJ: Erlbaum.

Stocker, C. M., Burwell, R. A., \& Briggs, M. L. (2002). Sibling conflict in middle childhood predicts children's adjustment in early adolescence. Journal of Family Psychology, 16, 50-57.

Stocker, C. M., \& McHale, S. M. (1992). The nature and family correlates of preadolescents' perceptions of their sibling relationships. Journal of Social and Personal Relationships, 9, $179-195$.

Stormshak, E. A., Bellanti, C. J., \& Bierman, K. L. (1996). The quality of sibling relationships and the development of social competence and behavioral control in aggressive children. Developmental Psychology, 32, 79-89.

Tucker, C. J., Barber, B. L., \& Eccles, J. S. (1997). Advice about life plans and personal problems in late adolescent sibling relationships. Journal of Youth and Adolescence, 26, 63-76.

Tucker, C. J., \& Updegraff, K. (2009). The relative contributions of parents and siblings to child and adolescent development. In L. Kramer \& K. J. Conger (Eds.), Siblings as agents of socialization. New directions for child and adolescent development (Vol. 126, pp. 13-28). San Francisco: Jossey-Bass.

Updegraff, K. A., Thayer, S. M., Whiteman, S. D., Denning, D. J., \& McHale, S. M. (2005). Relational aggression in adolescents' sibling relationships: Links to sibling and parent-adolescent relationship quality. Family Relations, 54, 373-385.

Volling, B. L., McElwain, N. L., \& Miller, A. L. (2002). Emotion regulation in context: The jealousy complex between young siblings and its relations with child and family characteristics. Child Development, 73, 581-600.

Youngblade, L. M., \& Dunn, J. (1995). Individual differences in young children's pretend play with mother and sibling: Links to relationships and understanding of other people's feelings and beliefs. Child Development, 66, 1472-1492.

Zukow-Goldring, P. (2002). Sibling caregivers. In M. H. Bornstein (Ed.), Handbook of parenting: Vol. 3: Being and becoming a parent (2nd ed., pp. 253-286). Mahwah, NJ: Erlbaum.

Received November 25, 2009

Revision received April 2, 2010

Accepted May 10, 2010

\section{E-Mail Notification of Your Latest Issue Online!}

Would you like to know when the next issue of your favorite APA journal will be available online? This service is now available to you. Sign up at http://notify.apa.org/ and you will be notified by e-mail when issues of interest to you become available! 